\title{
Minute Times Gram per Milliliter per Meter Squared
}

National Cancer Institute

\section{Source}

National Cancer Institute. Minute Times Gram per Milliliter per Meter Squared. NCI

Thesaurus. Code C111257.

Minutes times grams per milliliter, divided by meters squared. 